\title{
APPLICATION OF THE HYDROGEN CATHETER ELECTRODE IN THE DETERMINATION OF CORONARY BLOOD FLOW
}

\author{
Tomiyasu Koyama, Yoshiaki Marutani and Kinya Nakagawa \\ Department of Physiology, Research Institute of Applied Electricity, \\ Hokkaido University, Sapporo
}

\begin{abstract}
Summary The $\mathrm{H}_{2}$ catheter electrode was applied for the determination of the coronary blood flow to ascertain its applicability. First, a modified catheterization technique was newly introduced to facilitate the placing. of the catheter tip in the coronary sinus. Secondly, using this technique, the catheter electrode was inserted into the coronary sinus of dogs. Then, the $\mathrm{H}_{2}$ currents were measured in the aorta, coronary sinus and right atrium during the $\mathrm{H}_{2}$ inhalation to obtain the blood flow rate per unit volume of the heart tissue. This flow measurement was performed under three different experimental conditions of hypoxic respiration, epinephrine infusion and intravenous injection of carbochromen.

In comparison of the present results with the previous data obtained by other authors, it was demonstrated that the $\mathrm{H}_{2}$ current had sufficient accuracy and reproducibility to show the changes in coronary blood flow continuously over the long run of the experiment lasting for several hours. Unlike the results in the $\mathrm{N}_{2} \mathrm{O}$ method based on the coronary sinus blood sampling, the $\mathrm{H}_{2}$ desaturation curves recorded in the coronary sinus formed a straight line on the semilogarithmic scale. This suggested that the coronary blood flow observable in the coronary sinus might be almost uniform.
\end{abstract}

In the preceding paper (KoYAMA and MARUTANI, 1971) it was reported that the $\mathrm{H}_{2}$ catheter electrode is useful for the determination of the coronary blood flow. The flow rate obtained by this method can be evaluated by measuring the $\mathbf{P}_{\mathrm{H}_{2}}$ 's in both the coronary sinus and artery and it is generally expressed by a flow rate of $\mathrm{ml}$ blood per a unit volume of the heart per minute $(\mathrm{ml} / 100 \mathrm{ml} / \mathrm{min})$. Since the total individual heart volume can not be obtained, the absolute flow rate may not be obtained numerically. However, in the investigation of the effects of some chemical agents on the heart the use of this flow rate may be appropriate, since

Received for publication February 1, 1971

小山富康，丸谷義彰，中川欽也 
individual variation of the heart size may be disregarded.

ECKENHOFF et al. $(1947,1948)$ found that the nitrous oxide saturation curve obtained in the coronary sinus was similar to that obtained in the atrium and concluded that the coronary sinus blood was contaminated with the atrial. To sample the coronary blood, therefore, their recommendation was to secure the catheter tip tightly inside the cardiac vein. When the $\mathrm{P}_{\mathrm{H}_{2}}$ is measured directly at the catheter tip by using an $\mathrm{H}_{2}$ electrode, however, the blood sampling is not necessary. Therefore, because the blood flow is present in the vicinity of the electrode surface, apprehension as to whether the $\mathrm{P}_{\mathrm{H}_{2}}$ measured in the sinus would be affected by that of the atrium is unwarranted. Thus, it becomes desirable to leave a space between the catheter tip and the vascular inner wall to avoid disturbance of the blood flow, which might occur when the catheter tip is inserted deeply into the coronary vein as in the case of ECKENHOFF et al. $(1947,1948)$.

Hitherto, the coronary blood flow has usually been measured in open chest dogs, however, when it is technically possible to locate the catheter tip in the coronary sinus, the flow measurement should be made without opening the chest. Using this merit of the $\mathrm{H}_{2}$ electrode, its applicability was examined in dogs without resorting to severe surgery. In addition, with the intention of demonstrating an expected increase of the coronary blood flow, measurements were made under the following three different conditions of hypoxic respiration, infusion of epinephrine and intravenous injection of carbochromen. The reliability of the method was further tested by comparing results obtained with the data presented by other authors.

\section{METHODS}

Three $\mathrm{H}_{2}$ catheter electrodes were used for recording the $\mathrm{P}_{\mathrm{H}_{2}}$ 's in the aorta, coronary sinus and right atrium. In some cases two electrodes placed in the aorta and coronary sinus were used. The introduction of the catheter was made principally according to Goodale's technique (GoOdale et al., 1948), but it was found rather difficult to place the tip of the flexible conventional heart catheter in the desired position of the coronary sinus. To eliminate the technical difficulty a guide tube was improvised; this was a $30 \mathrm{~cm}$ long polyethylene tube with an outer diameter of $4 \mathrm{~mm}$ which was superimposed on the catheter at its distal end. The guide tube had a mild curvature of about 110 degrees at a point 1 to $2 \mathrm{~cm}$ from the tip. Since it had a suitable stiffness, the curvature was convenient for the introduction of the tip into the opening of the coronary sinus. As a preliminary step, the catheter was inserted through the tube so as to bring the electrode tip flush with the distal end of the tube, and the tube was fixed at its proximal end to the catheter by a rubber stopper which was previously set on the catheter. The inner lumen of the tube was filled with physiological saline solution by mild suction from the proximal end. With the aid of fluoroscopic observation the tip 
of the tube could easily be introduced into the opening of the coronary sinus via the exposed jugular vein. After the introduction, the guide tube was bound to the jugular vein and by gentle prodding of the catheter the tip was moved into the coronary sinus and further into the coronary vein. Then, the tube alone was carefully pulled out, so that the distal end of the tube is removed from the atrium to the jugular vein, leaving the catheter electrode in the coronary vein. Finally, the catheter also was drawn outwards, so as to position its tip in the coronary sinus.

The recording of the $\mathrm{H}_{2}$ current was made as described in the preceding paper (KoYAMA and MARUTANI, 1971) and the coronary blood flow was calculated from the recorded $\mathrm{H}_{2}$ desaturation curve according to KETY and SCHMIDT (1945).

Mongrel dogs were anesthetized by intravenous injection of sodium pentobarbital in a dose of $30 \mathrm{mg} / \mathrm{kg}$. Respiration was carried out through a tracheal cannula and a J-valve. In the hypoxia tests the hypoxic condition was maintained constantly for $10 \mathrm{~min}$, then, a cock in the inspiratory system was turned to introduce the gas mixture containing hydrogen. In order to keep the alveolar $\mathrm{P}_{\mathrm{O}_{2}}$ constant independent of the $\mathrm{H}_{2}$ inhalation, $\mathrm{O}_{2}$ concentrations in the inspired gases with or without $\mathrm{H}_{2}$ were kept equal to each other.

In 6 to $8 \mathrm{~min}$ after the onset of the $\mathrm{H}_{2}$ respiration the cock was returned to the previous $\mathrm{H}_{2}$ free gas mixture to wash out the $\mathrm{H}_{2}$ in the alveoli. The gas mixtures used had three levels of $\mathrm{O}_{2}$ concentration of $5.38,6.72$ and $10.85 \%$ equally in both cases with or without $\mathrm{H}_{2}$. The $\mathrm{H}_{2}$ concentration was usually lower than $5 \%$. Each gas was prepared in high pressure bombs. In the control experiment of air respiration the dogs were subjected to an alternate respiration of room air and a gas mixture of $4.80 \% \mathrm{H}_{2}, 20.81 \% \mathrm{O}_{2}$ and a balance of $\mathrm{N}_{2}$.

Epinephrine was infused into the femoral vein in three different dose rates of $0,0.5$, and $1.0 \mu \mathrm{g} / \mathrm{kg} / \mathrm{min}$. Carbochromen (Takeda, Osaka) which is known as a coronary vasodilating substance was injected intravenously in a dose of $2 \mathrm{mg}$ / $\mathrm{kg}$ and the coronary blood flow was measured at 15 and $45 \mathrm{~min}$ after the injection.

\section{RESULTS}

Figure 1 shows the $\mathrm{P}_{\mathrm{H}_{2}}$ changes in the aorta, coronary sinus and right atrium in four different experimental conditions of air respiration, epinephrine infusion, carbochromen injection and hypoxia. The $\mathrm{P}_{\mathrm{H}_{2}}$ changes were most rapid in the aorta, slower in the coronary sinus and the slowest in the atrium. The rate of the change depended on the flow rate, in detail, the time to reach the saturation points or the maximum plateaus varied according to the flow rate within a range of 2 to $7 \mathrm{~min}$. Figure $1 \mathrm{~A}$ shows the $\mathrm{P}_{\mathrm{H}_{2}}$ curves obtained in air respiration. Figure $1 \mathrm{~B}$ was obtained under intravenous infusion of epinephrine, where the $\mathrm{P}_{\mathrm{H}_{2}}$ change in the sinus became very rapid. Under the influence of carbochromen the curve was found to be less steep than in epinephrine infusion as shown in Fig. 1C, 


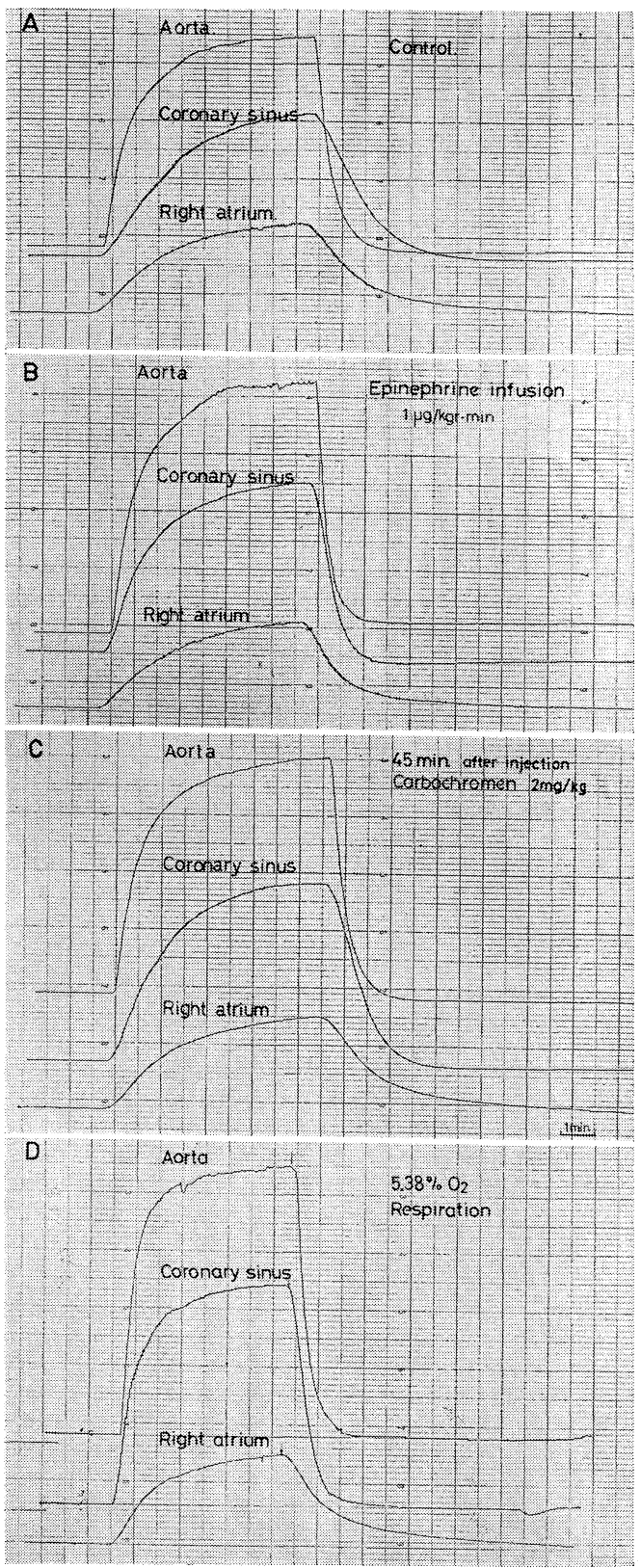

Fig. 1. Recordings of hydrogen concentration in the aorta, coronary sinus and right atrium of a single dog. A, Control; B, epinephrine infusion at a rate of $1.0 \mu \mathrm{g} / \mathrm{kg} / \mathrm{min} ; \mathrm{C}$, intravenous injection of carbochromen in a dose of $2 \mathrm{mg} / \mathrm{kg}$; D, respiration of $5.38 \%$ oxygen. 
but clearly steeper than in the control of air respiration. In the hypoxic respiration the $\mathrm{H}_{2}$ curve of the coronary sinus became remarkably steep.

Figure 2 shows the desaturation or washout curves obtained in three different cases of hypoxia, epinephrine and carbochromen administrations from top to bottom, where the $\mathrm{P}_{\mathrm{H}_{2}}$ was expressed in percentage of the maximum plateau value. All the curves were obtained one after another in the same dog employed for obtaining the data of Fig. 1. Figure $2 \mathrm{~A}$ shows the curves measured in three different $\mathrm{P}_{\mathrm{O}_{2}}$ levels of $20.81,10.85$ and $5.38 \% \mathrm{O}_{2}$ gas inhalations. The calculated coronary blood flows were 99,165 and $426 \mathrm{ml} / 100 \mathrm{ml} / \mathrm{min}$ in the above cases, respectively. Figure 2B shows the $\mathrm{H}_{2}$ curves during epinephrine infusion under three different dose rates of $0,0.5$ and $1.0 \mu \mathrm{g} / \mathrm{kg} / \mathrm{min}$. When $0.5 \mu \mathrm{g} / \mathrm{kg} / \mathrm{min}$ was given, the blood flow increased from 99 up to $160 \mathrm{ml} / 100 \mathrm{ml} / \mathrm{min}$ and when the dose rate was doubled, the flow rate increased further to $325 \mathrm{ml} / 100 \mathrm{ml} / \mathrm{min}$. Figure $2 \mathrm{C}$ shows the desaturation processes measured 15 and 45 minutes after the intravenous injection of carbochromen in a dose of $2 \mathrm{mg} / \mathrm{kg}$, where the calculated flow rates were 232 and $147 \mathrm{ml} / 100 \mathrm{ml} / \mathrm{min}$, respectively. In the recording of Fig. 1 all the saturation processes proceeded more slowly than the desaturation for unknown reasons. Even when the blood flow, however, was calculated from the saturation curves the obtained values showed no systematic difference from those obtained using desaturation process.

Figure 3 shows the relationship between the coronary blood flow and $\mathrm{O}_{2}$ concentration in inspired gases obtained in 15 dogs. The coronary blood flow at $\mathrm{O}_{2}$ concentrations of $20.92,10.85,6.72$ and $5.38 \%$ were found to be $93.6,128.5$, 310.2 and $454.5 \mathrm{ml} / 100 \mathrm{ml} / \mathrm{min}$ on average, respectively. The standard deviations were $24.3(n=23), 25.7(n=11), 62.0(n=12)$ and $92.3(n=4)$, respectively, where $n$ denotes the number of experiments. The above average flow rates in hypoxia correspond to $146.8,331.5$ and $485.0 \%$ of the rate of the control, showing a wide variability of the coronary blood flow. In parallel with the coronary blood flow, the aortic blood pressure and the heart rate also increased as the $\mathrm{P}_{\mathrm{O}_{2}}$ was decreased. The mean aortic pressures together with the standard deviations in four cases of the above were 121.9 $\pm 14.7,135.0 \pm 15.0,142.6 \pm 10.0$ and 184.0 $\pm 10.2 \mathrm{mmHg}$ and the heart rates were $165.2 \pm 26.0,164.0 \pm 29.0,204.8 \pm 15.0$ and $212.6 \pm 11.6$ beats/min. During severe hypoxia the R-spike of ECG was lowered in most cases, and arhythmia appeared at times.

Figure 4 shows the effect of carbochromen of the coronary blood flow in relation to the elapsed time after the injection of carbochromen. In six dogs carbochromen was intravenously injected in a dose of $2 \mathrm{mg} / \mathrm{kg}$. In all dogs the coronary blood flow increased clearly. On an average the control value was $79.8 \pm 15.3 \mathrm{ml} / 100 \mathrm{ml} / \mathrm{min}$, while 15 and $45 \mathrm{~min}$ after the injection the calculated flow rates were $132.5 \pm 54.0 \mathrm{ml} / 100 \mathrm{ml} / \mathrm{min}(P<0.05)$ and $99.8 \pm$ $28.5 \mathrm{ml} / 100 \mathrm{ml} / \mathrm{min}(P<0.10)$, respectively. These flow rates corresponded to $166.0 \pm 67.5$ and $124.7 \pm 35.6 \%$ of the control value. The mean aortic pressure 

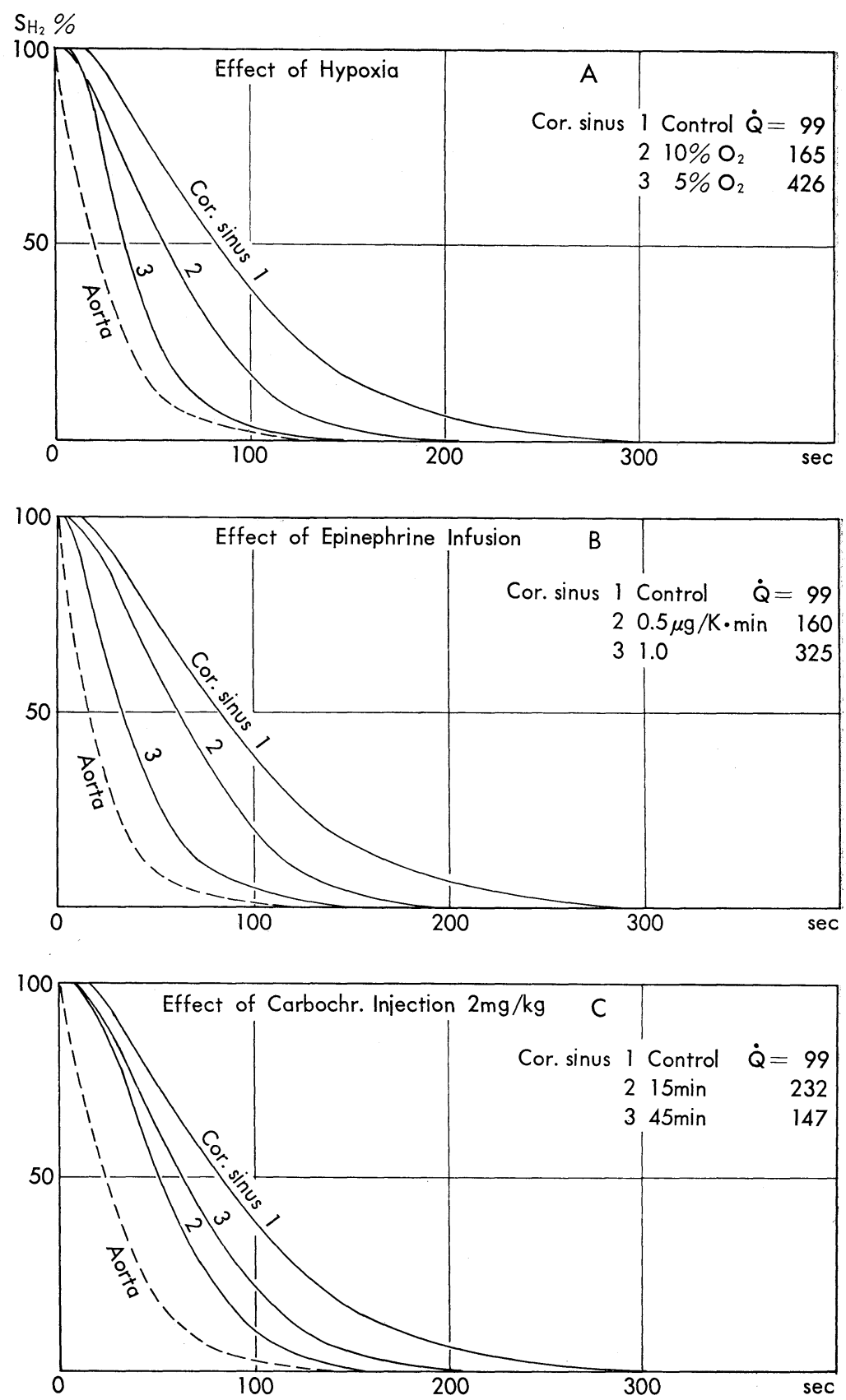

Fig. 2. Tracings of the desaturation curves in the same dog as in Fig. 1 under various conditions of hypoxic respiration, epinephrine infusion and treatment with carbochromen. 


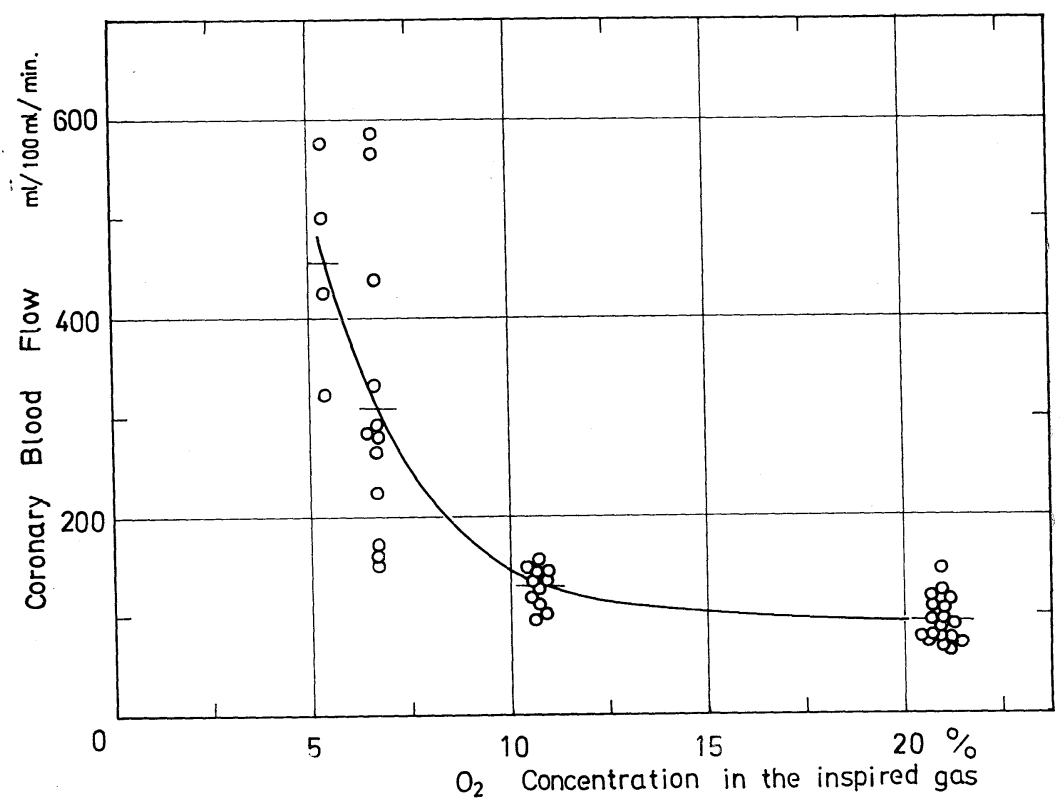

Fig. 3. The relation between the coronary blood flow observed and the oxygen concentration of the inspired gases. The thin horizontal lines indicate the average values.

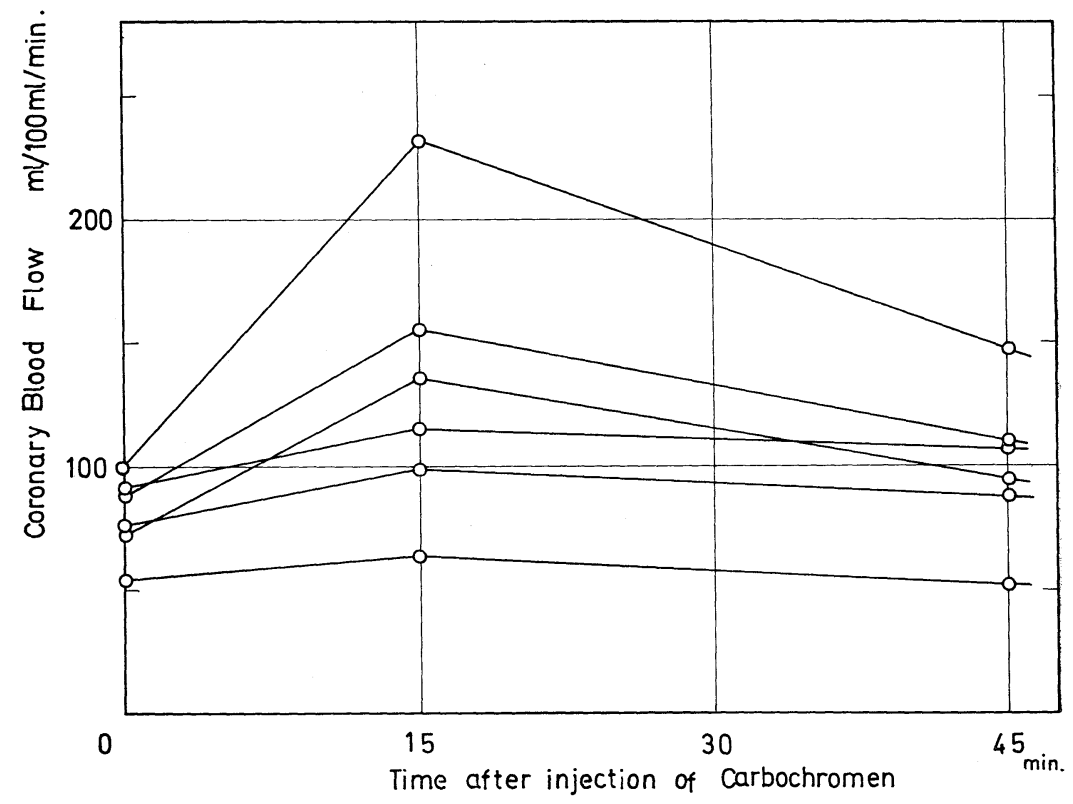

Fig. 4. Coronary blood flow obtained 15 and 45 minutes after intravenous injection of carbochromen in six dogs. 


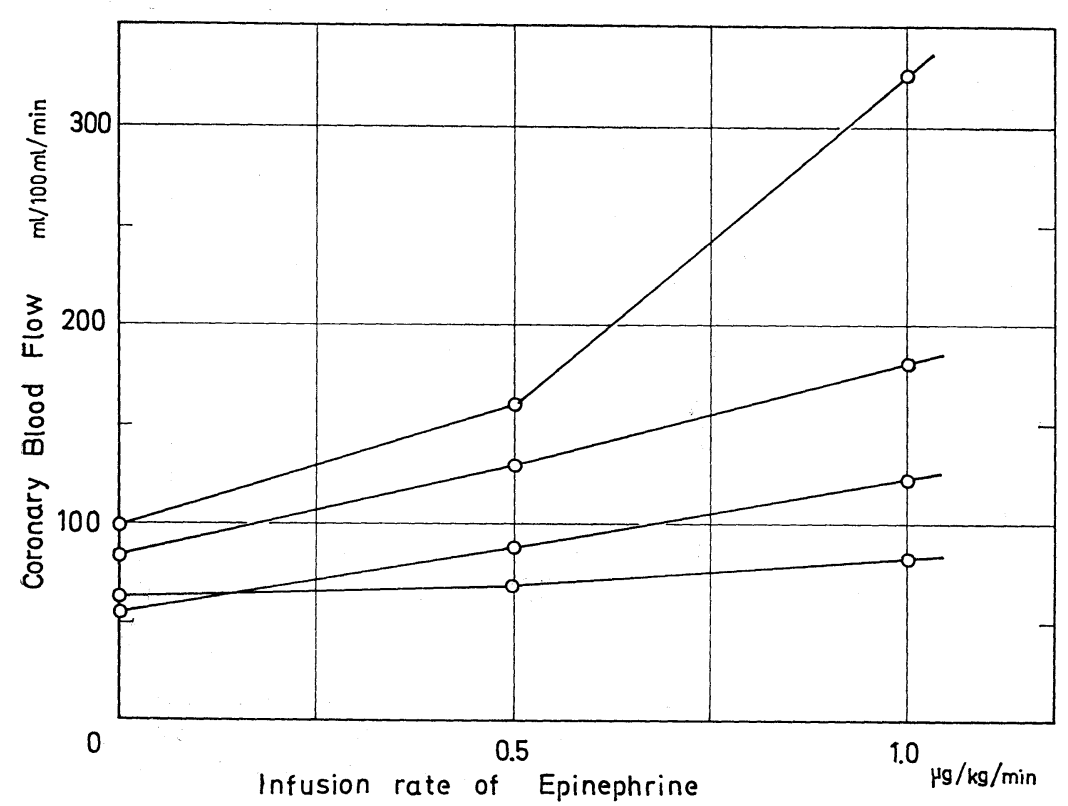

Fig. 5. Coronary blood flow observed under intravenous infusion of epinephrine in four dogs.

and the heart rate showed no definite changes.

In four dogs the effects of epinephrine infusion were investigated at dose rates of 0.5 and $1.0 \mu \mathrm{g} / \mathrm{kg} / \mathrm{min}$. The drug did not always increase the coronary blood flow but a considerable variation was observed in measured flow rates as shown in Fig. 5. The flow rates ranged from 132 to $330 \%$ of the respective control values. The responses in the heart rate as well as in the mean aortic pressure also differed from case to case. In one dog which showed only a slight increase in coronary blood flow both the heart rate and mean aortic pressure showed a slight decrease by epinephrine infusion. In another dog which showed considerable increase in coronary blood flow the heart rate decreased at a dose rate of $1.0 \mu \mathrm{g} / \mathrm{kg} / \mathrm{min}$, while the mean aortic pressure increased steadily. In other words, no consistent tendencies were observed in either the heart rate or the mean aortic pressure. Thus, it may be said that the dogs employed showed a considerable individual variation in response to epinephrine infusion.

In Fig. 6 the three $\mathrm{H}_{2}$ curves in the coronary sinus shown in Fig. 1 were replotted at every $40 \mathrm{sec}$ on a semilogarithmic scale against the elapsed time. All curves showed a linear decrease, indicating a homogeneous blood flow through the coronary vessels in spite of the regional variation in dimension of individual vascular routes.

The curves obtained in the atrium may reflect the blood flow through the 


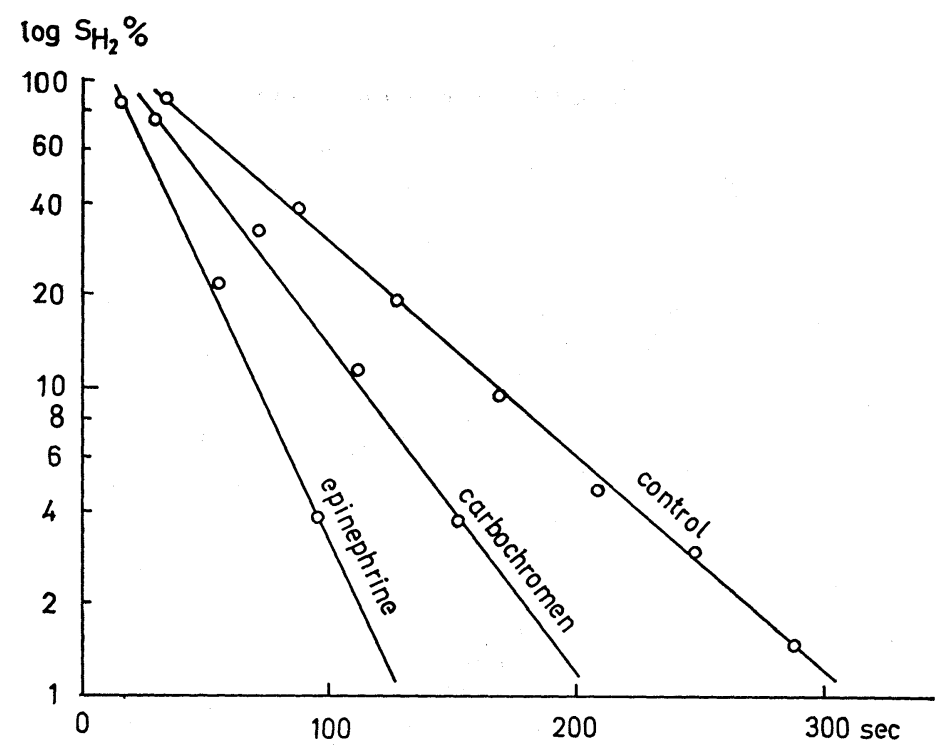

Fig. 6. Semilogarithmic plotting of the hydrogen desaturation curves of Fig. 1.

entire body, where individual vascular routes should be different from part to part of the body. Thus, it was expected that the $\mathrm{H}_{2}$ curve in the atrium would deviate from such a simple exponential curve as shown in Fig. 6. Consequently, it seemed rather difficult to obtain an average blood flow through the entire body from the $\mathrm{H}_{2}$ curve. As an example to show the specific characteristic of this $\mathrm{H}_{2}$ curves, logarithms of the $\mathrm{P}_{\mathrm{H}_{2}}$ 's in the atrium and the coronary sinus were plotted against time in both the cases of control and epinephrine infusion in Fig. 7. The atrial $\mathrm{H}_{2}$ curve was found to be multiexponential and was tentatively resolved into two components as shown with the broken lines in Fig. 7. For each component the blood flow could be calculated by replotting each of the broken lines on a linear scale and by applying the method by Kety and Schmidt. In the control experiment the fast component yielded a flow rate of $59.0 \mathrm{ml} / 100 \mathrm{ml} / \mathrm{min}$ and the slow component showed a flow rate of $17.0 \mathrm{ml} / 100 \mathrm{ml} / \mathrm{min}$. Epinephrine infusion made the slope of the fast component steeper and that of the slow, less steeper than that of the respective component in the control, i.e. the flow rates were 117.5 and $14.7 \mathrm{ml} / 100 \mathrm{ml} / \mathrm{min}$.

\section{DISCUSSION}

As for the effect of continuous hypoxic conditions ECKENHOFF et al. (1948) found that the coronary blood flow was increased from 66.0 to $150 \mathrm{ml} / 100 \mathrm{ml}$ / min in dogs in $8 \% \mathrm{O}_{2}$ inhalation, and HACKel et al. (1954) reported that the coro- 

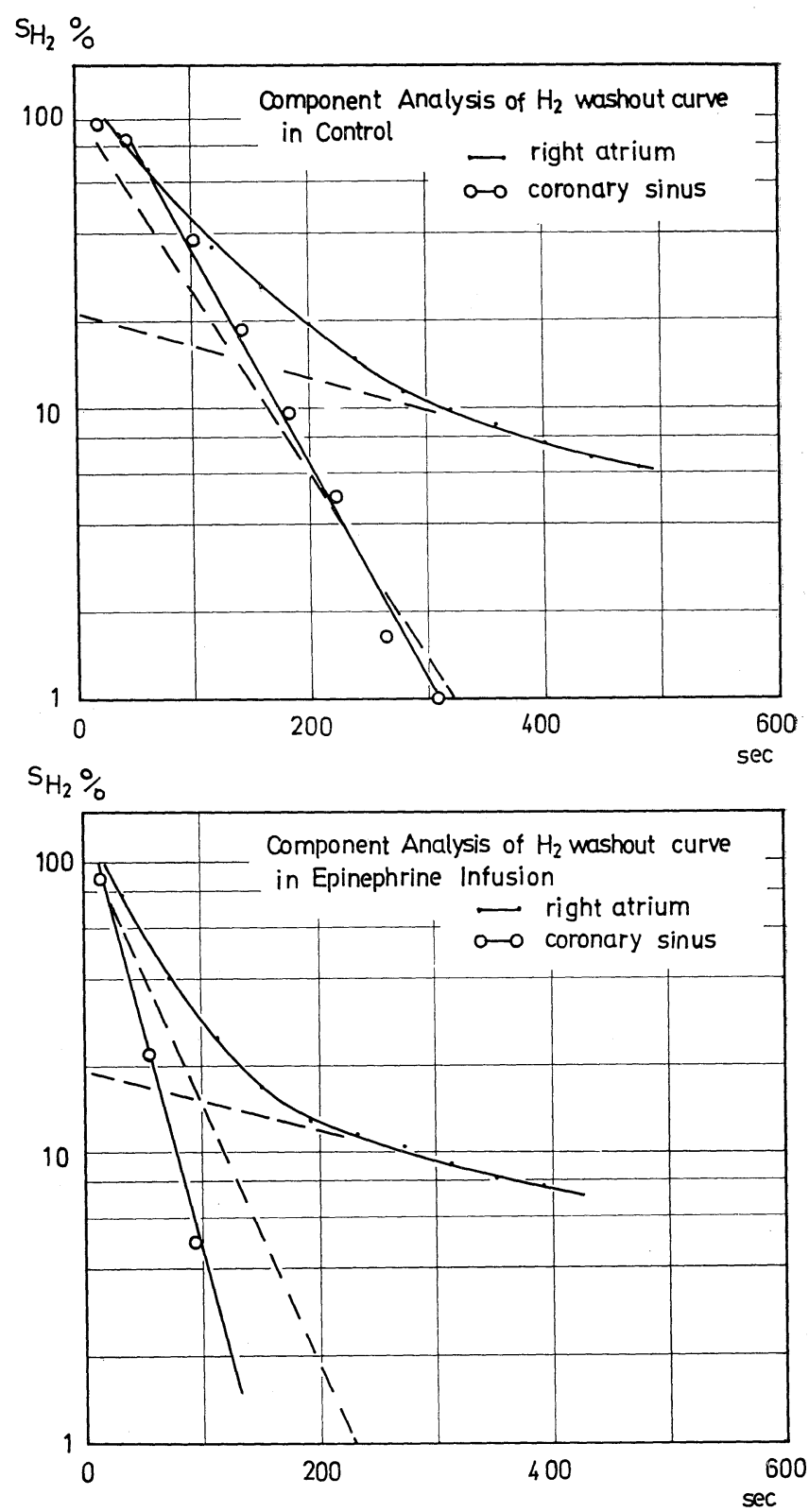

Fig. 7. An example of component analysis of $\mathrm{H}_{2}$ desaturation curves replotted from Fig. 1A and B. The atrial curve was tentatively divided into two linear broken lines. 
nary blood flow increased from 116.8 to 193.3 in $10 \% \mathrm{O}_{2}$ inhalation and from 126.3 to $502.5 \mathrm{ml} / 100 \mathrm{ml} / \mathrm{min}$ in $5 \% \quad \mathrm{O}_{2}$ inhalation, which coincided with the present results.

According to Nitz and PöTzsch (1963) the coronary blood flow increased by $66 \%$ of the control value at $15 \mathrm{~min}$ after an injection of $2 \mathrm{mg} / \mathrm{kg}$ of carbochromen and $25 \%$ at $45 \mathrm{~min}$. RUDOLPH et al. (1967) found an increase of $45 \%$ at $15 \mathrm{~min}$. In the present study the increase of coronary blood flow was 66.0 and $24.7 \%$ at 15 and $45 \mathrm{~min}$, respectively, which were in good agreement with the previous data described above.

The effect of epinephrine on the coronary blood flow have hitherto been studied by observing the influence of a single injection thereof. PITT et al. (1967) found a $194 \%$ increase following a single intravenous injection of $1.0 \mu \mathrm{g} / \mathrm{kg}$ of epinephrine using an implanted magnetic flowmeter. Because of the difference in procedure of giving epinephrine, their results can not be compared directly with ours. In our experiments the coronary blood flow clearly increased in three dogs out of four with the administration of epinephrine. Therefore, at least in that a strong increase of the coronary flow was found, our data agreed with theirs.

ECKENHOFF et al. (1948) found that the $\mathrm{N}_{2} \mathrm{O}$ desaturation curve in the coronary sinus was similar to that in the atrium. On the other hand, KIRK and HoNIG (1964) reported a nonuniform distribution of capillary vessels through the myocardium. However, as shown in Fig. 6 the $\mathrm{H}_{2}$ desaturation curves in the coronary sinus apparently showed a straight line on a semilogarithmic scale under three different conditions. This seems to suggest that the coronary blood flow was almost uniform through the entire region of the heart muscle. Recently, we found in another experiment that the coronary flow was different in quantity more or less in various layers of the myocardium. Therefore, it may be conceivable that the regional variation of the coronary flow is not so large as to be detectable by the $\mathrm{H}_{2}$ desaturation curve obtained in the coronary sinus.

As reported in the preceding paper KoYAMA and MARUTANI (1971) a linear relation between the $\mathrm{H}_{2}$ current and $\mathrm{P}_{\mathrm{H}_{2}}$ can only be obtained in a narrow range of the measuring conditions. However, such conditions were not so difficult to obtain, i.e. when optimum conditions for thickness of the platinum black layer, tightness of the covering Teflon membrane, and so on were attained, the linear calibration curve could be obtained. On the other hand, in order to know the $\mathrm{P}_{\mathrm{H}_{2}}$ from the $\mathrm{H}_{2}$ current it was necessary to maintain the $\mathrm{P}_{\mathrm{O}_{2}}$ in the measuring. site constant. In the measurement of the coronary blood flow, it is necessary in general to keep the $\mathrm{P}_{\mathrm{O}_{2}}$ in the myocardium as constant as possible. Therefore, the $\mathrm{P}_{\mathrm{O}_{2}}$ 's of the inspired gases with and without $\mathrm{H}_{2}$ were carefully adjusted to a constant level. Then, the influences of some extrinsic agents exerted on the coronary vessels may be appreciated with accuracy.

Another undesirable drawback of the present method for the flow measurement seems to lie in length of time required to know the flow rate which exceeds 
10 minutes. This drawback is essentially concerned with diffusibility and solubility of $\mathrm{H}_{2}$ in the muscle as well as the volume ratio of the flowing blood and the muscle tissue of the heart. For instance, if the $\mathrm{H}_{2}$ molecules were as less diffusible as dyes generally used in a dye dilution method, the blood flow velocity may be obtained in a very short time. However, in such a case the flow rate per a unit volume of the heart could never be obtained. Therefore, it should be recognized that in order to appreciate the blood volume flowing through the unit volume of the organ tissue a length of time such as 10 to $15 \mathrm{~min}$ becomes absolutely necessary. Thus, the technical drawback of requiring a considerable length of time, rather than being the end result of using the $\mathrm{H}_{2}$ electrode, may be the intrinsic limitation of this type of measurement.

The authors wish to express their thanks to Prof. M. Mochizuki, Director of the Research Institute of Applied Electrocity, Hokkaido University for his valuable suggestions in the present study.

\section{REFERENCES}

Eckenhoff, J. E., Hafkenshiel, J. H., Landmesser, C. M. and Harmel, M. (1947) Cardiac oxygen metabolism and control of the coronary circulation. Amer. J. Physiol., 149: 634 649.

Eckenhoff, J. E., Hafkenshiel, J. H., Harmel, M. H., Goodale, W. T., Lubin, M., Bing, R. J. and KETY, S. S. (1948) Measurement of coronary blood flow by the nitrous oxide method. Amer. J. Physiol., 152: 356-364.

Goodale, W. T., Lubin, M., Eckenhoff, J. E., Hafkenshiel, J. H. and Banfield, W. G. (1948) Coronary sinus catheterization for studying coronary blood flow and myocardial metabolism. Amer. J. Physiol., 152: 340-354.

HaCkel, D. B., Goodale, W. T. and Kleinerman, J. (1954) Effects of hypoxia on the myocardial metabolism of intact dogs. Circ. Res., 2: 169-174.

Kety, S. S. and Schmidt, C. F. (1945) The determination of cerebral blood flow in man by the use of nitrous oxide in low concentration. Amer. J. Physiol., 143: 53-66.

KIRK, E. S. and HoNIG, C. R. (1964) Nonuniform distribution of blood flow and gradients of oxygen tension within the heart. Amer. J. Physiol., 207: 661-668.

KoyAmA, T. and MARUTANI, Y. (1971) Hydrogen catheter electrode as a device for determination of blood flow through tissue. Japan. J. Physiol. 21: 209-228.

Nitz, R. E. und Pötzsch, E. (1963) 3-(beta-Diäthylamino-äthyl)-4-methyl-7-Carbäthoxymethoxy-2-oxo-(1, 2-chromen), ein Präparat mit spezifischer und lang anhaltender Coronargefäss erweiternder Wirkung. Arzneim. Forsch., 13: 243-251.

PitT, B., Elliot, E. C. and GRegG, D. E. (1967) Adrenergic receptor activity in the coronary arteries of the unanesthetised dog. Circul. Res., 21: 75-84.

RudolPh, W., Meixner, L. und KüNZIG, H. J. (1967) Pharmakodynamische Beeinflussung von Coronardurchblutung und Stoffwechsel des menschlichen Herzens, Untersucheungen mit 3-(beta-Diäthylamino-äthyl)-4-methyl-7-carbäthoxy-methoxy-2-oxo-(1,2-chromen)-hydrochlorid. Klin. Wschr., 45: 333-353. 